\title{
MONITORING OF MASJED-SOLEIMAN EMBANKMENT DAM'S DEFORMATION USING A COMBINATION OF INTERFEROMETRIC SYNTHETIC APERTURE RADAR (INSAR) AND FINITE ELEMENT MODELING
}

\author{
Saeed AMINJAFARI \\ Department of Surveying and Geomatics Engineering, University of Tehran, Tehran, Iran \\ E-mail: aminjafari@alumni.ut.ac.ir
}

Received 6 December 2016; accepted 13 February 2017

\begin{abstract}
The fresh water shortage is one the most important challenges in many countries like Iran. So there have been incentives to manipulate and manage water resources by constructing dams. Clay core embankments are one of the most popular dam structures. A layer of clay can be a reliable obstacle in front of water stream. However, because of the soil's nature, these kinds of dams have the potential of instability. Thus deformation of clay core dams should be monitored frequently. The aim of this study is to use the combination of Interferometric Synthetic Aperture Radar technique (InSAR) and Finite Element Modeling (FEM) for dam's deformation monitoring. For the InSAR analysis we used data from ENVISAT sensor and processed those using Small BAseline Subset (SBAS). We show that InSAR is an invaluable approach to monitor clay core dam's deformation in specific circumstances. The deformation derived from InSAR was used as an initial condition in Finite Element Modeling. The case study is Masjed Soleiman Dam which is situated in South West of Iran. We used 19 ASAR images of ENVISAT sensor from 2003/8/22 to 2010/5/7. The process of ASAR images showed maximum velocity of $11 \mathrm{~mm} /$ year in LOS direction at central lower areas of dam. These results were compared with Geodetic Surveying Operations at four points on dam and the average agreement of 77 percent was obtained. The results of ENVISAT data have a good consistency with FEM results. Horizontal and vertical displacements derived from instrumentations and modeling are plotted versus depths. There is a good agreement between modeling results and instrumentations data.
\end{abstract}

Keywords: insar, finite element modelling, deformation, embankment.

\section{Introduction}

Since any failure in embankments leads to enormous financially and human losses, frequent deformation monitoring of embankments is vital and inevitable. There are a wide variety of approaches for structure monitoring including conventional geodetic operation, close range photogrammetry, laser scanning and global positioning system. However, due to spectacular features like all weather and time measurements, high spatial resolution and comprehensive data collection, InSAR could be a reliable and powerful tool to observe structures movements. In addition, this method does not require direct contact with construction. So, several works concerning the InSAR capability of deformation monitoring have been put forward (Luo et al. 2011; Honda et al. 2012; Perissin et al. 2009; Wang et al. 2011; Monells et al. 2010; Hooper et al. 2012; Voege et al. 2012; Di Martire et al. 2014; Milillo et al. 2016; Shamshiri et al. 2014).

Embankment dam modeling empowers engineers to predict dam behavior under loadings like water force, dam weight and consolidation phenomena. Also they can determine the source of dam failure to take immediate actions. In this study obtained displacements of InSAR method have been imported as an initial condition in modeling.

Initially 19 ASAR images of ENVISAT sensor between years 2003 and 2010 have been employed. The wavelength of images is 56 millimeter and incidence angle is approximately 23 degrees. The SBAS method implemented in StaMPS software (Hooper et al. 2012) have been used to acquire time series deformation. 


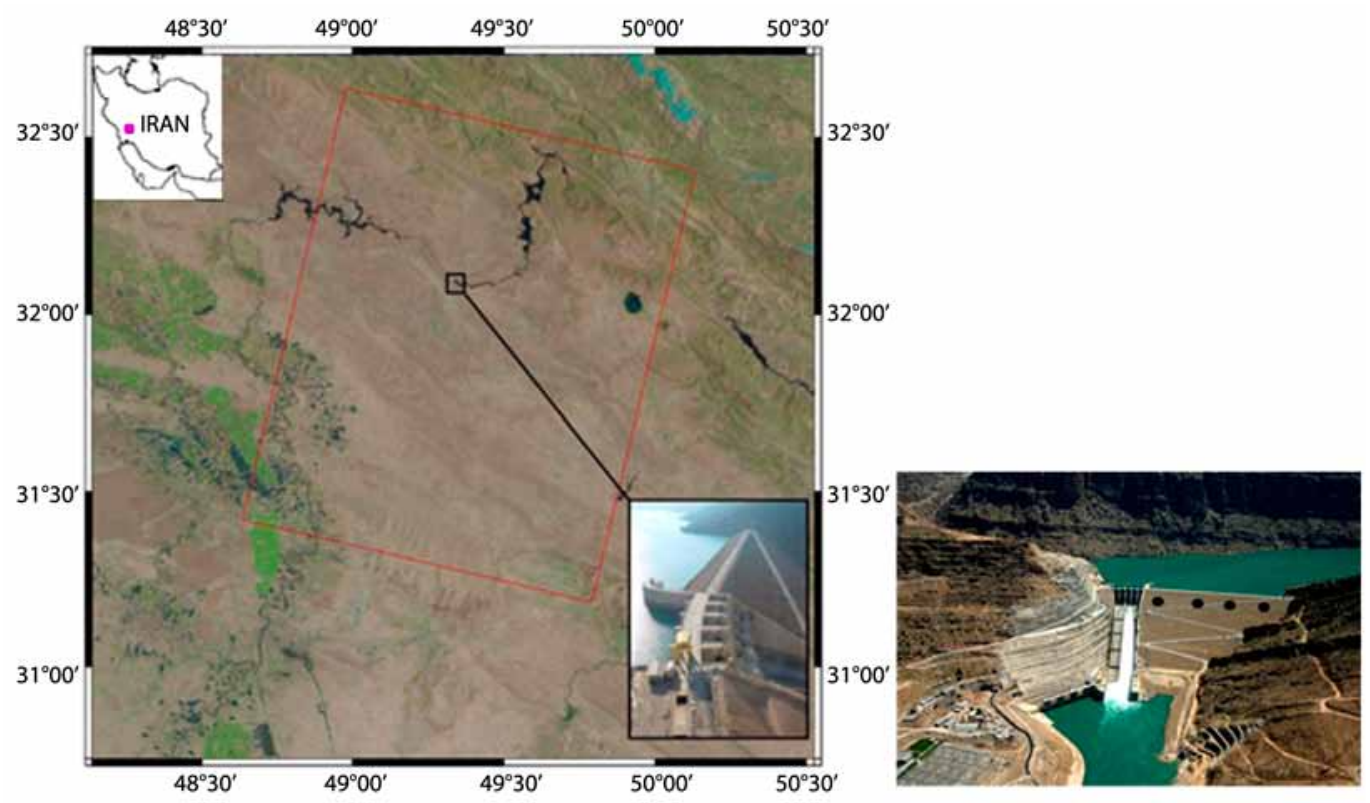

Fig. 1. Masjed Soleiman Dam, it's Location, SAR image frame and geodetic points of Figure 2 (black points)

Due to poor quality and correlation, 6 images between years 2003 and 2004 were processed ultimately.

Since Karoun River is the longest river $(950 \mathrm{~km})$ of Iran and has the highest level of water, notable number of dams has been constructed along it and Masjed Soleiman Dam is one of them. Masjed Soleiman Dam is a hydropower dam which is located south west of Iran in Masjed Soleiman City. Construction of dam was finished in year 2000 and was operated in that year. This dam is capable of producing $2000 \mathrm{MW}$ electricity now. Catchment basin of dam is $25829 \mathrm{~km}^{2}$ and its elevation is 177 meter from foundation and 172 meter from riverbed. Dam crest is 15 meters wide and 488 meters long. Masjed Soleiman dam is a clay core dam (Fig. 1).

\section{Methodology}

\subsection{Time series extraction by SBAS}

The SBAS implemented in StaMPS has been used in this study. The network was obtained by pair images with these conditions: time interval less than 1500 day, perpendicular baseline less than 1050 meters and coherence greater than 0.35 .

The phase noise can be estimated from the interferometric SAR pair by means of the local coherence. The local coherence is the cross-correlation coefficient of the SAR image pair estimated over a small window. The coherence value ranges from 0 (the interferometric phase is just noise) to 1 (complete absence of phase noise) (Ferretti et al. 2007).
Instability of scatterers, incidence angle and antenna pattern deviation of squint result in decorrelation. Therefore, the time differences of pairs must be as minimum as possible to minimize the decorrelation of scatterers instability (Hooper 2006, 2008). Decorrelation of squint and incidence angle deviation could be minimized by means of a suitable band pass filter. SBAS method is looking for Slow Varying Filtered Phased (Hooper 2008).

Processing steps are as follows:

First of all, a network of appropriate interferograms is constructed. It should be mentioned that all images are filtered in range and azimuth direction to remove geometric decorrelation and non-overlaying part of Doppler spectrum. So the coherence of pixels will be maximized (Hooper 2008; Kampes et al. 2003).

SBAS is interested in pixels with negligible phase due to non-spatial decorrelated term of noise. Spatially correlated terms are estimated by using a band pass filter. Also non-spatial decorrelated term of DEM error is proportional to perpendicular baseline. Consequently, non-spatial decorrelated term of noise could be calculated simply (Hooper 2006).

In order to reduce calculations and accelerate process, phase instability $(\gamma)$ of pixels with small Amplitude Dispersion Index (ADI) is estimated:

$$
\gamma=\frac{1}{N}\left|\sum_{i=1}^{N} e^{i\left(\varphi_{\text {int }}-\tilde{\varphi}_{\text {int }}-\widehat{\Delta \varphi_{D E M}^{N C}}\right)}\right| .
$$

$N$ denotes the number of interferograms, $\tilde{\varphi}_{\text {int }}$ is estimation of spatially correlated parts and $\widehat{\Delta \varphi_{D E M}^{N C}}$ 
is estimation of non-spatially decorrelated phase of DEM. Pixels with higher value of $\gamma$ are more likely to be a SFP. Average phase of selected SFP's and also $\gamma$ are calculated during a repetitive process which leads to noise reduction. It is necessary to choose a threshold value for $\gamma$. The Probability density function of whole data is proportion to probability density function of random pixels and SFP's:

$$
P(\gamma)=(1-\alpha) P_{r}(\gamma)+\alpha P_{S F P}(\gamma) \text {. }
$$

Participation probability of random pixels must be smaller than a certain value:

$$
q=\frac{(1-\alpha) \int_{\gamma^{t}}^{1} P_{r}(\gamma) d \gamma}{\int_{\gamma^{t}}^{1} P(\gamma) d \gamma} .
$$

It is possible to consider no probability for SFP's that the $\gamma$ for them is less than 0.3 . So the value of $\alpha$ and $\gamma$ threshold are obtained:

$$
\int_{0}^{0.3} P(\gamma) d \gamma=(1-\alpha) \int_{0}^{0.3} P_{r}(\gamma) d \gamma
$$

In order to detect the wrongly omitted SFP's with high ADI, the process of calculating $\gamma$ will be done for them (Hooper 2006).

Finally, the unwrapped phase equation reads:

$$
\varphi_{u w}=\varphi_{\text {def }}+\varphi_{\text {atm }}+\Delta \varphi_{\text {orb }}+\Delta \varphi_{D E M}^{\text {Corr }}+\Delta \varphi_{n}+2 k \pi,
$$

where $\Delta \varphi_{n}$ is the spatially decorrelated phase of noise.

\section{Deformation phase retrieval}

The remained phases of recent equation are spatially correlated. However, they consist of both temporally correlated and decorrelated parts. The temporally correlated phases are due to atmospheric noise and orbit errors of master image. So they exist in all interferograms. Since phase $2 \mathrm{k} \pi$ has made the phase equation temporally decorrelated, it is impossible to utilize a low pass filter in time domain. With the aim of removing $2 \mathrm{k} \pi$ phase, unwrapped differential phase among adjacent pixels is calculated using Delaunay triangulation. Therefore a low pass filter is applicable and temporally correlated phase will be eliminated (Hooper 2006).

A high pass filter could estimate temporally decorrelated phases. The remained noise phase will be omitted by means of a low pass filter in space domain. Lastly the deformation phase will be acquired by estimated phases (Hooper 2006):

$$
\begin{gathered}
\varphi_{\text {def }} \approx \varphi_{u w}+\widehat{\varphi_{a t m}^{m}}-\widehat{\varphi_{a t m}^{s}}+\widehat{\varphi_{o r b}^{m}}- \\
\widehat{\varphi_{a t m}^{s}}-\Delta \varphi_{D E M}^{C o r r}-\Delta \varphi_{n}-2 k \pi .
\end{gathered}
$$

\subsection{Finite element modeling}

The modeling of materials with linear elastic behavior could be done by means of conventional analytical computing methods. But in case of nonlinear elastoplastic behaviors an advanced numerical approach is desirable which can be solved by a computer software (Gunduz 2008). In this study the PLAXIS software was used (Brinkgreve et al. 2006).

There are a wide range of numerical methods of modeling including finite volume, finite element and finite difference. Finite element is an effective way to solve partial differential and integral equations by converting them to ordinary equations. A uniform structure is divided into a number of elements and stress and strain will be calculated in these elements numerically. The elements are connected by nodes which have a degree of freedom. Since stress and strain are available, other parameters like deformation are obtainable simply (Ottosen, Petersson 1992).

The behavior of an element could be defined by a mathematical equation named behavioral model (Gunduz 2008). Depending on materials and loadings, there are lots of behavioral models. Problems with dynamic loadings or creep could be solved by time variant behavioral models. However, in case of static problems with linear elastic, nonlinear elastic and elastoplastic materials, time invariant models are applicable. Embankment dams are massive, anisotropic, heterogeneous and inelastic soil structures which have contact with water and foundation (Segerlind 1984; Dassault Systèmes 2011).

An ideal model should have three main features (Ottosen, Petersson 1992; Dassault Systèmes 2011):

(1) Material behavior should be simulated as reality under all loading circumstances.

(2) The model should be simple and based on ordinary mathematical equations.

(3) The number of required parameters should be as lowest as possible and acquirable by conventional soil experiments.

Due to nonlinear inelasticity behavior of soils, an ideal model is critical. In case of inappropriate models, the results would not be accurate and reliable (Dassault Systèmes 2011).

In this study elastoplastic hardening soil model has been applied. This model is a complicated model which simulates behavior of all kind of soft and hard soils. When initial deflection loading is applied to soil, its hardening will be decreased and irreversible plastic strain will be increased. The relation of axial strain 
and deflection stress could be estimated in conditions of drained triaxial experiment. It is possible to use the hardening model instead of hyperbola model by means of plasticity theory instead of elasticity theory, soil dilation angle and defining a yield surface.

\section{Validation data}

Planning and creation of a precise geodetic network around and on a structure is one the most reliable and conventional method to control deformations of that structure. The geodetic network of Masjed Soleiman dam has been planned before dam operation and the field surveying operations have been done in 10 periods so far. The value and direction of network point's deformations on dam from step one to the last step have been depicted in Figure 2.

Also horizontal and vertical displacements of dam along depth are collected by instrumentations to validate modeling results.

\section{Results and discussion}

The image of 2004/12/24 was chosen as master image since the perpendicular and temporal baseline of this image related to another images were small enough. Primary interferograms were created under these conditions: coherence greater than 0.35 , perpendicular baseline less than 1070 meter and temporal baseline less than 1500 day. Low quality of interferograms resulted in reduction of SFP's. So the images of low quality interferograms were discarded. Finally, 6 images were processed and 15 interferograms were produced (Fig. 3).

At the end of SBAS process the residuals of all interferograms are less than Pi. Five main unwrapped interferograms have been plotted in Figure 4. Main interferograms have been produced by master image. Deformations are shown in radian unit. The asterisk is the reference point. Topographic phase has been removed by digital elevation model of Shuttle Radar Topography Mission (SRTM) (Jarvis et al. 2008). Flatten earth phase, orbital phase and noise have almost been eliminated.

No significant deformation has been detected between years 2003 and 2004 because dam operation has been done in year 2000 and major changes have happened in first years of operation.

The maximum value of phase difference is observed in image of 26 Sep 2003. Then the image of 5 Dec 2003 has the most phase difference related to master image. One of the reasons is water level changes

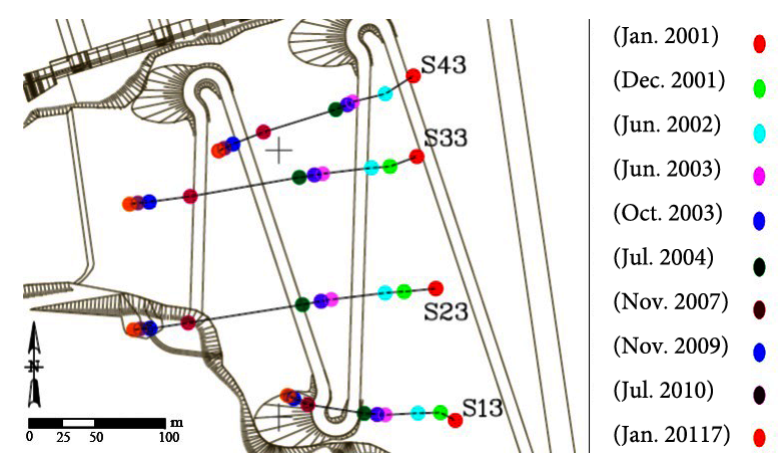

Fig. 2. Direction and value of horizontal displacements of geodetic stations

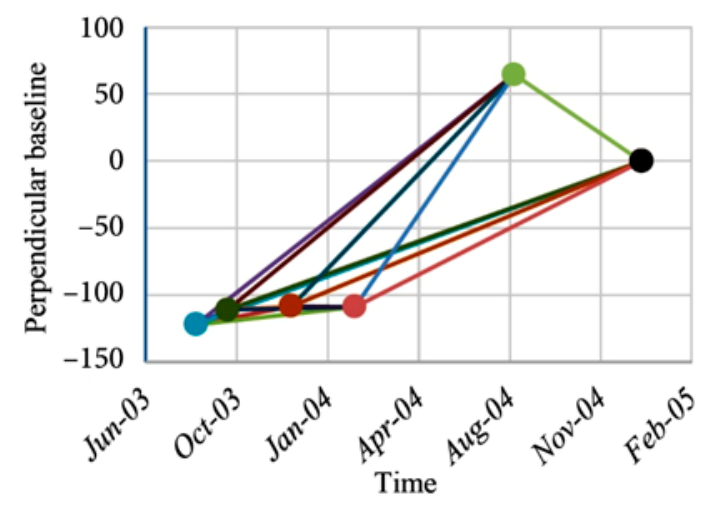

Fig. 3. SBAS network
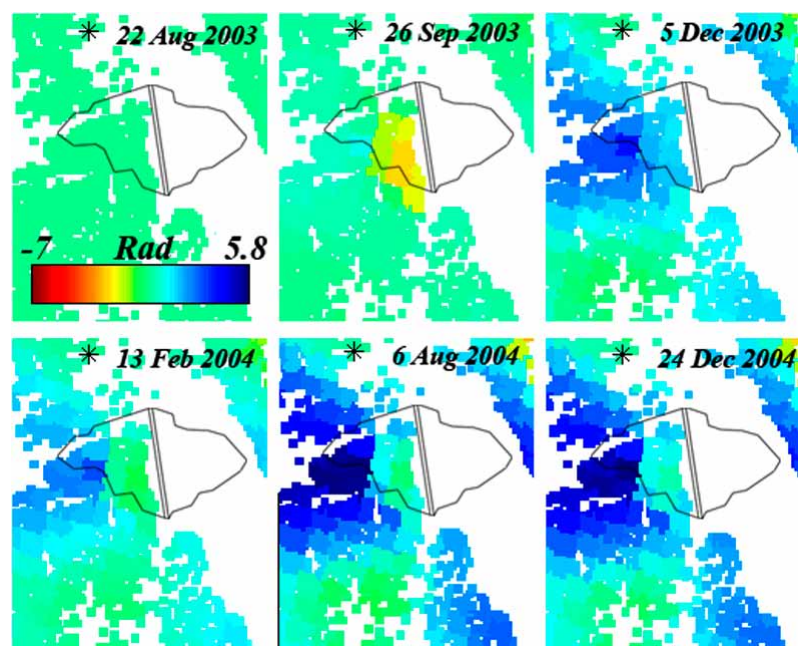

Fig. 4. Main unwrapped interferograms due to master image

between 22 Aug 2003 and 5 Dec 2003 (4.5 meter). The pattern of water level changes in 2004 is similar to what happened in 2003. In summer water level has increased and in winter has decreased. This water level variation has contributed to dam deformation which is depicted as phase differences in interferograms. However, this deformation is too small.

At the end of SBAS processing map of deformation velocities has been retrieved. Figure 5 shows the 


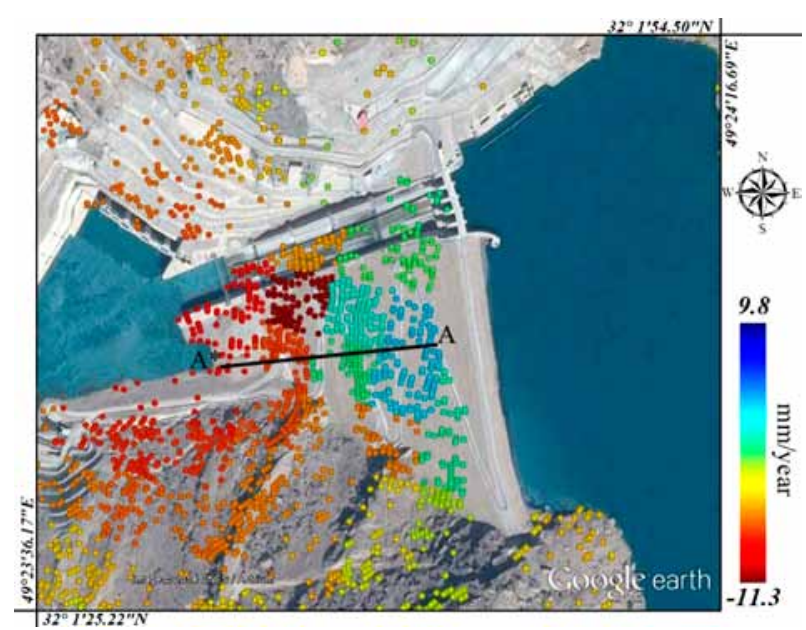

Fig. 5. Velocity map on Google Earth

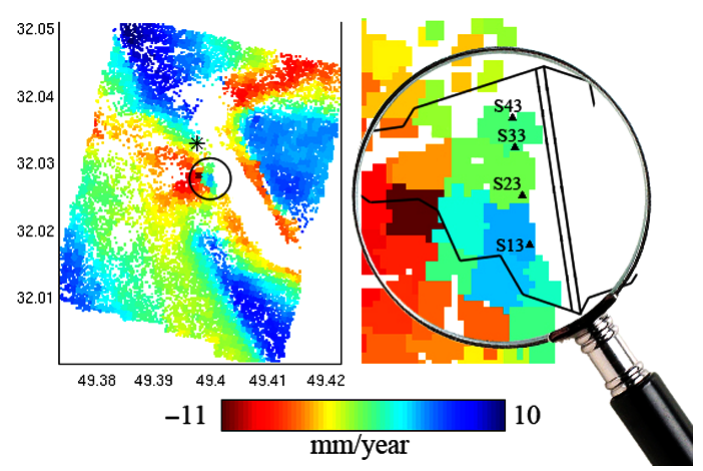

Fig. 6. Location of geodetic stations on velocity map

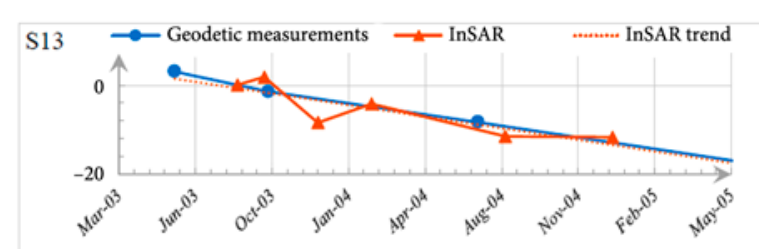

S23
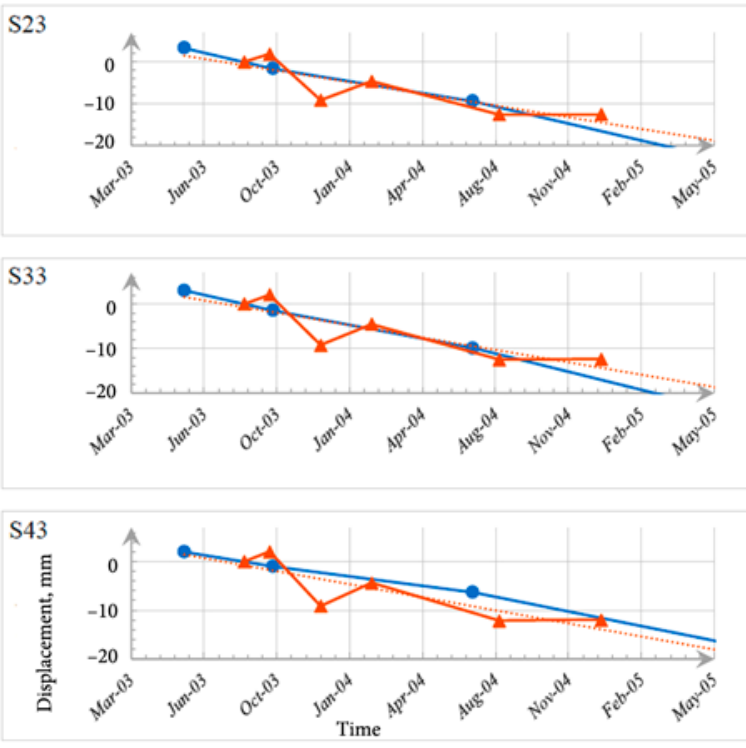

Fig. 7. Comparison of InSAR results and geodetic measurements velocity map on Google Earth. The middle part of dam moves faster than other parts $(3.5 \mathrm{~mm} /$ year in direction of Line of Sight). The rate of displacement at lateral sides has declined to $1 \mathrm{~mm}$ /year.

Geodetic components of deformation should be transformed to LOS direction to comprise field surveying operation displacements with SBAS results. Eq. (7) is used to transform a three dimensional displacement field to LOS direction (Shamshiri et al. 2014):

$$
d_{L O S}=-d_{x} \cos \alpha \sin \theta+d_{y} \sin \alpha \sin \theta+d_{z} \cos \theta,(7)
$$

where $d_{x}, d_{y}$ and $d_{z}$ are components of deformation, $\theta$ is incidence angle and $\alpha$ is satellite azimuth.

Figure 6 shows the location of comprised points on the dam.

Time interval between first and last image is 490 days. Deformation derived by geodetic measurements has been referred to the reference point of SBAS method spatially and date of master image temporally.

Figure 7 shows the comparison of geodetic measurements and SBAS deformations. Normalized Root Mean Square Errors of points S13, S23, S33 and S43 are $20 \%, 22 \%, 23 \%$ and $26 \%$. So the average NRMSE is $23 \%$.

\section{Finite element modeling}

Since cross section of 260 meter is the most elevated section, it has been modeled in a plain strain modeling. The main cofferdam with materials of gravel and a temporary crown has been unified with main dam at outer upstream layer. The elevation of dam from lowest part of core trenching is 164 meter. The steepness of upstream is 1 to 2 and downstream steepness is 1 to 1.75. Also the roads are 6 meter wide. Dam crest width is 15 meter. Figure 8 and Figure 9A show longitudinal and 260 cross section of dam.

Hyperbola hardening soil model was used to model dam body and Mohr-coulomb model was utilized for foundation modeling. These models parameters of materials are listed in Table 1 and Table 2.

15 -node triangular elements were implemented in modeling. The final mesh had 4725 elements, 38211 nodes, 56700 stress points. Figure 9B has shown meshed dam.

Roller anchor $(u x=0 u y=$ free $)$ at lateral sides of foundation and joint anchor at the floor of foundation were applied (Fig. 9B) (Segerlind 1984). Water level data has been used to produce initial pore water pressure.

There are six calculation phases. Initial stresses were produced at phase one and deformations were 


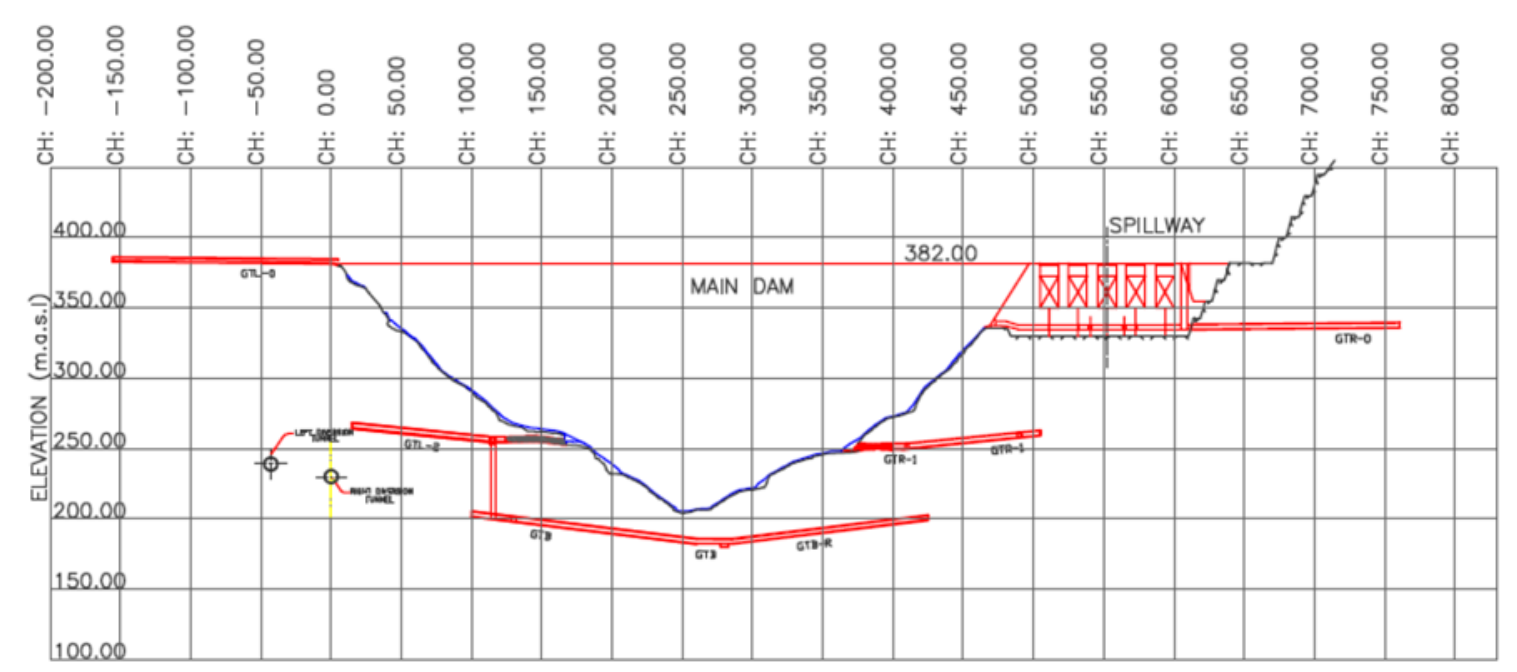

Fig. 8. Longitudinal section of Masjed Soleiman Dam

a)

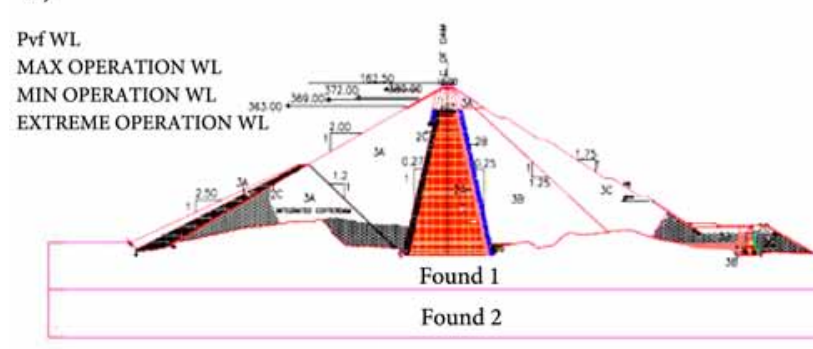

c)

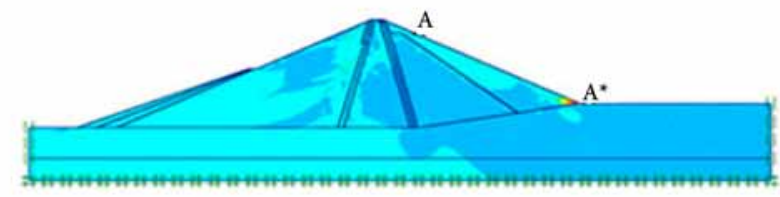

b)

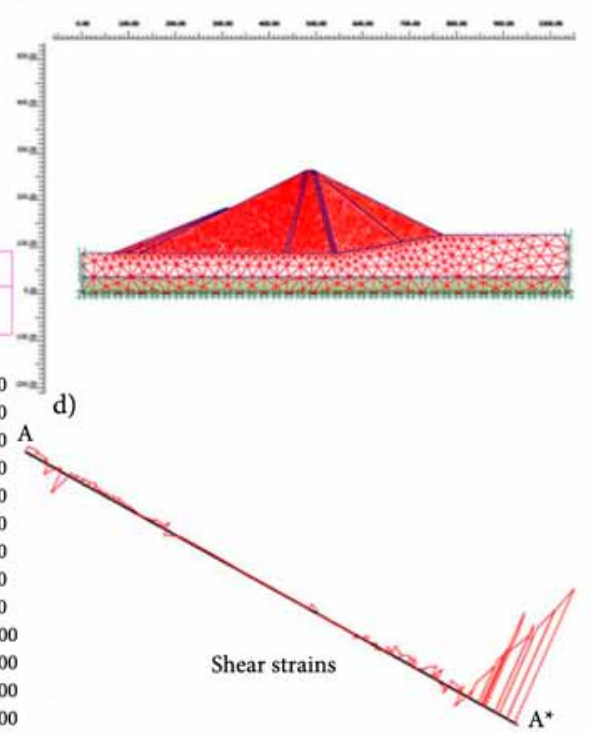

Fig. 9. 260 Cross section of Masjed Soleiman Dam(A), Meshed dam(B), Shear strain (C), Shear strain along line $A^{\star}(D)$

Table 1. Material property of dam body in HS model

\begin{tabular}{|c|c|c|c|c|c|c|c|}
\hline Material & $2 \mathrm{~A}$ & $2 \mathrm{~B}$ & $2 \mathrm{C}$ & $3 \mathrm{~A}$ & $3 \mathrm{~B}$ & $3 \mathrm{C}$ & 1 (Core) \\
\hline Type & Drained & Drained & Drained & Drained & Drained & Drained & UnDrained \\
\hline$\gamma_{\text {unsat }}\left(\mathrm{kN} / \mathrm{m}^{3}\right)$ & 20.5 & 18.3 & 22.9 & 13.5 & 22.9 & 13.5 & 21.5 \\
\hline$\gamma_{\text {sat }}\left(\mathrm{kN} / \mathrm{m}^{3}\right)$ & 23.2 & 19.7 & 23.2 & 13.5 & 23.9 & 13.5 & 22.5 \\
\hline$K_{x}(\mathrm{~m} /$ day $)$ & 0.39 & 0.39 & 0.009 & 0.15 & 0.005 & 0.15 & $9 \mathrm{e}-6$ \\
\hline$K_{y}(\mathrm{~m} /$ day $)$ & 0.32 & 0.32 & 0.002 & 0.18 & 0.008 & 0.18 & $1.3 \mathrm{e}-6$ \\
\hline$E_{50}^{r e f}\left(\mathrm{kN} / \mathrm{m}^{2}\right)$ & 72000 & 37000 & 126000 & 94000 & 95000 & 94000 & 28000 \\
\hline$E_{\text {oed }}^{r e f}\left(\mathrm{kN} / \mathrm{m}^{2}\right)$ & 72000 & 56676 & 126000 & 91563 & 95000 & 91563 & 27650 \\
\hline \multirow{2}{*}{$E_{u r f}^{r e f}\left(\mathrm{kN} / \mathrm{m}^{2}\right)$} & 216000 & 111000 & 378000 & 282000 & 285000 & 282000 & 84000 \\
\hline$c^{\text {ref }}\left(\mathrm{kN} / \mathrm{m}^{2}\right)$ & 0 & 0 & 0 & 0 & 0 & 0 & 12 \\
\hline$\varphi(\mathrm{deg})$ & 35 & 41 & 41 & 45 & 41.7 & 45 & 30.9 \\
\hline$\psi(\mathrm{deg})$ & 5 & 11 & 11 & 15 & 2 & 15 & 0 \\
\hline$v_{u r}$ & 0.2 & 0.2 & 0.2 & 0.2 & 0.2 & 0.2 & 0.2 \\
\hline$P_{r e f}\left(\mathrm{kN} / \mathrm{m}^{2}\right)$ & 1200 & 600 & 1200 & 1200 & 300 & 1200 & 600 \\
\hline Power & 0.5 & 0.5 & 0.5 & 0.35 & 0.35 & 0.35 & 0.7 \\
\hline
\end{tabular}


Table 2. Material property of dam foundation in Mohrcoulomb model

\begin{tabular}{|c|c|c|}
\hline Material & Found 1 & Found 2 \\
\hline Type & Drained & Drained \\
\hline$\gamma_{\text {unsat }}\left(\mathrm{KN} / \mathrm{m}^{3}\right)$ & 23 & 24 \\
\hline$\gamma_{\text {sat }}\left(\mathrm{KN} / \mathrm{m}^{3}\right)$ & 24 & 25 \\
\hline$K_{x}(\mathrm{~m} /$ day $)$ & 0.0086 & 0.8640 \\
\hline$K_{y}(\mathrm{~m} /$ day $)$ & 0.0086 & 0.8640 \\
\hline$v$ & 0.3 & 0.3 \\
\hline$E_{r e f}\left(\mathrm{KN} / \mathrm{m}^{2}\right)$ & 38772200 & 6776400 \\
\hline$c_{r e f}\left(\mathrm{KN} / \mathrm{m}^{2}\right)$ & 700 & 2000 \\
\hline$\varphi(\mathrm{deg})$ & 30 & 45 \\
\hline$\psi(\mathrm{deg})$ & 0 & 12 \\
\hline
\end{tabular}

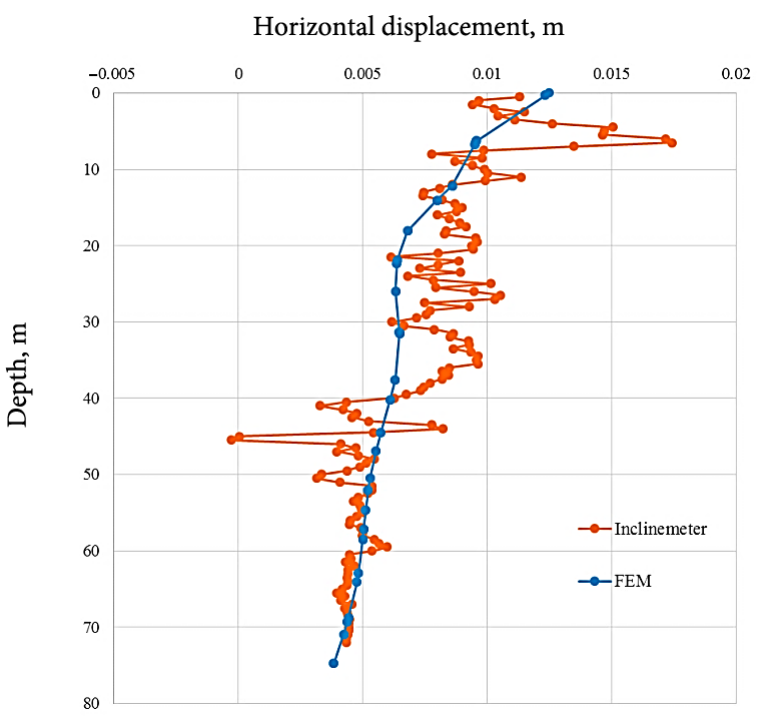

Fig. 10. Evaluation of horizontal displacements of modeling and instrumentations versus depth

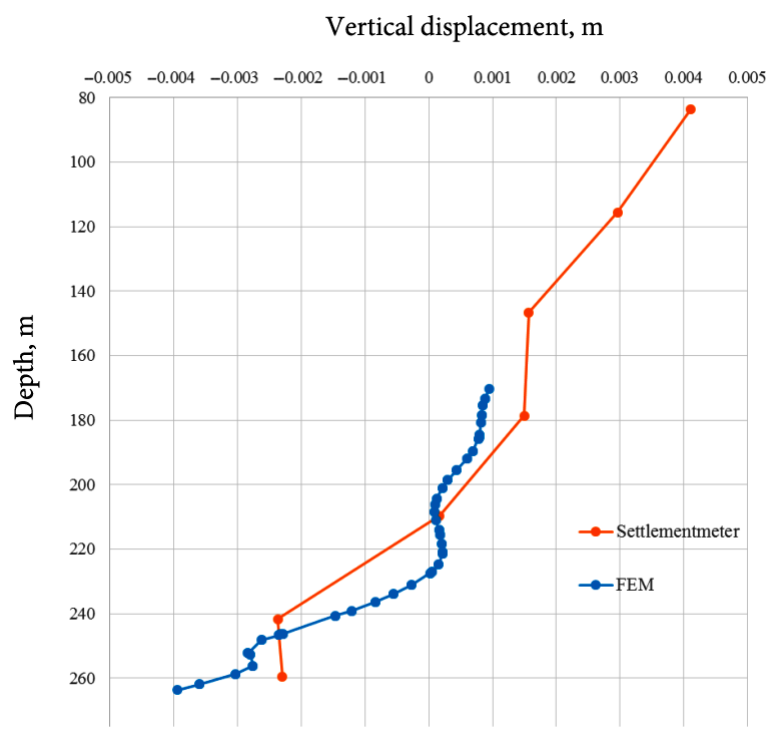

Fig. 11. Evaluation of vertical displacements of modeling and instrumentations versus depth calculated at the other phases. According to time difference between first image and last image, the time interval of modeling is 490 days. Deformation derived from SBAS has been imported as an initial condition in modeling.

Figure 9C illustrates shear strain at the end of processing. Also shear train in $\mathrm{AA}^{*}$ direction was plotted in Figure 9D.

This is observed that shear strain has reached to a maximum value at the lowest elevation of downstream. $\mathrm{AA}^{*}$ line has been drawn on the velocity map in Figure 5. High deformation gradients in the lowest elevation of downstream have a good consistency with modeling results.

In order to validate modeling results the instrumentations data of dam were obtained. Inclinometer and settlement meter measure horizontal and vertical movements. These measurements versus depth are plotted along with modeling results. Figure 10 and Figure 11 shows the evaluation.

\section{Conclusions}

The purpose of this study is to examine the displacements of embankment dams. The time history of embankment deformations has been retrieved using Interferometric SAR. Subsequently the deformations derived from InSAR have been used as an initial condition in Finite Element Modeling. Due to valuable features including non-contact measurements, all weather compatibility and high spatial resolution, InSAR is a powerful tool to obtain surface movements with an acceptable accuracy. Moreover, it is possible to be aware of dam behavior in future and investigate the source of its displacements using FEM. At first 19 ASAR images of ENVISAT sensor with $56 \mathrm{~mm}$ wavelength and incidence angle of 23 degrees was processed. Lastly 6 images between years 2003 and 2004 were selected for final processing. The validation has been done for four points on the dam body by precise field surveying operations. The comparison shows a good agreement between Interferometry results and geodetic measurements. The retrieved NRMSE is between 20\% and $26 \%$. Furthermore, calculated horizontal and vertical displacements in modeling were compared with instrumentations data. The results approve that modeling has a good consistency with instrumentations.

\section{References}

Bonano, M.; Manunta, M.; Marsella, M.; Lanari, R. 2012. Longterm ERS/ENVISAT deformation time-series generation 
at full spatial resolution via the extended SBAS technique, International Journal of Remote Sensing 33(15): 4756-4783. https://doi.org/10.1080/01431161.2011.638340

Brinkgreve, R.; Broere, W.; Watterman, D. 2006. PLAXIS $2 D$. Ver 8. Scientific Manual. Delft University of Technology, Netherlands.

Dassault Systèmes. 2011. Abaqus 6.11 [online]. Documentation [cited 29 December 2013]. Available from Internet: http:// mat1.uibk.ac.at/download/stix/Abaqus\%206.11\%20Documentation/

Di Martire, D.; Iglesias, R.; Monells, D.; Centolanza, G.; Sica, S.; Pagano, L.; Mallorquì, J. J.; Calcaterra, D. 2014. Comparison between Differential SAR interferometry and ground measurements data in the displacement monitoring of the earth-dam of Conza della Campania (Italy), Remote Sensing of Environment 148C: 58-69.

https://doi.org/10.1016/j.rse.2014.03.014

Ferretti, A.; Monti-Guarnieri, A.; Prati, C.; Rocca, F.; Massonet, D. 2007. InSAR principles-guidelines for SAR interferometry processing and interpretation. Vol. 19. European Space Agency.

Gunduz, B. 2008. Analysis of settlements of test embankments during 50 years - a comparison between field measurements and numerical analysis: MSc Thesis. Department of Construction Sciences, Lund University, Sweden.

Honda, K.; Nakanishi, T.; Haraguchi, M.; Mushiake, N.; Iwasaki, T.; Satoh, H.; Kobori, T.; Yamaguchi, Y. 2012. Application of exterior deformation monitoring of dams by DInSAR analysis using ALOS PALSAR, in International Geoscience and Remote Sensing Symposium (IGARSS), 22-27 July 2012, IEEE, 6649-6652. https://doi.org/10.1109/igarss.2012.6352074

Hooper, A. 2008. A multi temporal InSAR method incorporating both persistent scatterer and small baseline approaches, Geophysical Research Letters 35(16). https://doi.org/10.1029/2008GL034654

Hooper, A. J. 2006. Persistent scatter radar interferometry for crustal deformation studies and modeling of volcanic deformation: PhD Thesis. Stanford University.

Hooper, A.; Bekaert, D.; Spaans, K.; Arikan, M. 2012. Recent advances in SAR interferometry time series analysis for measuring crustal deformation, Tectonophysics 514-517: 1-13. https://doi.org/10.1016/j.tecto.2011.10.013

Jarvis, A..; Reuter, H. I..; Nelson, A.; Guevara, E. 2008. Holefilled SRTM for the globe Version 4 [online]. CGIAR-CSI SRTM 90m Database [cited 21 January 2014]. Available from Internet: http://srtm.csi.cgiar.org

Kampes, B.; Hanssen, R.; Perski, Z. 2003. Radar Interferometry with Public Domain Tools, in Proc. of FRINGE 2003 Workshop, 1-5 December 2003, Frascati, Italy.

Luo, Q.; Perissin, D.; Lin, H.; Li, Q.; Duering, R. 2011. Railway subsidence monitoring by high resolution INSAR time series analysis in Tianjin, in $19^{\text {th }}$ International Conference on Geoinformatics, 24-26 June 2011, IEEE, 1-4.

https://doi.org/10.1109/geoinformatics.2011.5980745

Milillo, P.; Perissin, D.; Salzer, J. T.; Lundgren, P.; Lacava, G.; Milillo, G.; Serio, C. 2016. Monitoring dam structural health from space: insights from novel InSAR techniques and multi-parametric modeling applied to the Pertusillo dam Basilicata, Italy, International Journal of Applied Earth Observation and Geoinformation 52: 221-229. https://doi.org/10.1016/j.jag.2016.06.013

Monells, D.; Centolanza, G.; Mallorqui, J. J.; Duque, S.; LópezDekker, P.; Tomás, R.; Herrera, G.; López-Sánchez, J. M.; Vicente, F.; Navarro-Sanchez, V. D.; Mulas, J. 2010. Application of TerraSAR-X data to the monitoring of urban subsidence in the city of Murcia, in International Geoscience and Remote Sensing Symposium (IGARSS), 25-30 July 2010, IEEE, 3506-3509. https://doi.org/10.1109/igarss.2010.5652623

Ottosen, N. S.; Petersson, H. 1992. Introduction to the finite element method. NewYork, USA: Prentice Hall.

Perissin, D.; Prati, C.; Rocca, F.; Wang, T. 2009. PSInSAR analysis over the Three Gorges Dam and urban areas in China, in Joint Urban Remote Sensing Event, May 2009, IEEE, 1-5.

Segerlind, L. J. 1984. Applied finite element analysis. USA: Wiley.

Shamshiri, R.; Motagh, M.; Baes, M.; Sharifi, M. 2014. Deformation analysis of the Lake Urmia causeway (LUC) embankments in northwest Iran: insights from multi-sensor interferometry synthetic aperture radar (InSAR) data and finite element modeling (FEM), Journal of Geodesy 88(12): 1171-1185. https://doi.org/10.1007/s00190-014-0752-6

Voege, M.; Frauenfelder, R.; Larsen, Y. 2012. Displacement monitoring at Svartevatn dam with interferometric SAR, in International Geoscience and Remote Sensing Symposium, July 2012, IEEE, 3895-3898.

https://doi.org/10.1109/igarss.2012.6350561

Wang, T.; Perissin, D.; Rocca, F.; Liao, M. S. 2011. Three Gorges Dam stability monitoring with time-series InSAR image analysis, Science China Earth Sciences 54(5): 720-732. https://doi.org/10.1007/s11430-010-4101-1

Saeed AMINJAFARI is a researcher in National Cartographic Center of Iran (NCC). He received his master of science in Geodesy from University of Tehran. His recent publications include "Persian Gulf and Oman Sea Tide Modelling Using Satellite Altimetry and Tide Gauge Data(TM-IR01)" (2016 Conference: Geomatics 95, Tehran, Iran) and "Determination and evaluation of geostrophic circulations using satellite altimetry data in the northern Indian Ocean" (2016 Conference: Geomatics 95, Tehran, Iran). His research interests include the InSAR applications, Geo-hazard and satellite altimetry and he is currently completing studies of unification of height datum in Iran and subsidence monitoring of Iran's vallies. 